\title{
Hepatitis B virus testing and linkage to care in a Canadian urban tertiary referral centre: a retrospective cohort study
}

\author{
Keith C.K. Lau BHSc, Abdel Aziz Shaheen MD, Alexander A. Aspinall MD, Tazuko Ricento BA, \\ Kamran Qureshi MBA, Stephen E. Congly MD, Meredith A. Borman MD, Saumya Jayakumar MD, \\ Bertus Eksteen MD, Samuel S. Lee MD, Laura Stinton MD, Mark G. Swain MD, Kelly W. Burak MD, \\ Carla S. Coffin MD
}

\section{Abstract}

Background: Despite universal vaccination, chronic hepatitis B virus (HBV) infection remains a public health concern in North America owing to immigration. We aimed to characterize the number of people with a positive result of testing for HBV surface antigen (HBsAg) in Calgary, a large urban Canadian health care region, and to assess whether recommended laboratory tests and specialist consultation were done for those identified as HBsAg-positive.

Methods: Based on laboratory and Alberta Health Services administrative data, we identified all adults (age $>18$ yr) with a positive HBsAg test result from Jan. 1 to Dec. 31, 2014 within the Calgary Zone. Demographic and relevant laboratory data were extracted within 6 months of a positive HBsAg test result, and referral to hepatology (2011-2014) was identified from data on referral to a centralized clinic. Parametric and nonparametric statistical methods were used for analyses.

Results: We identified $1214 \mathrm{HBsAg-positive} \mathrm{people} \mathrm{(584} \mathrm{women} \mathrm{[48.1 \% ];} \mathrm{median} \mathrm{age} 44$ [interquartile range (IQR) 36-55] yr). A total of 1192 people $(98.2 \%)$ had alanine aminotransferase testing (median level 23 [IQR 16-34] U/L; 117 [9.8\%] with elevated levels), 682 (56.2\%) had testing for HBV DNA (median level 2.8 [IQR 2.1-3.8] loglU/mL), 630 (51.9\%) had HBV e antigen testing (negative result in 548 [87.0\%]), and $145(11.9 \%)$ had HBV e antibody testing (positive result in 111 [76.6\%]). Overall, 144 people (11.9\%) received anti-HBV treatment, and 390 (32.1\%) were referred to a hepatologist.

Interpretation: Many HBsAg-positive people in Calgary did not receive the recommended laboratory assessments. The results highlight the necessity of continual public health efforts to screen for chronic HBV infection in Canada and to ensure adequate follow-up in order to reach the World Health Organization's goal of viral hepatitis elimination by 2030.

$\sqrt{\tau}$ epatitis B virus (HBV) is a major global pathogen, with an estimated 240 million chronic HBV carriers worldwide, ${ }^{1,2}$ especially in Asia and sub-Saharan Africa. Despite universal childhood vaccination in Canada since the mid-1990s, chronic HBV infection (positive test result for hepatitis B surface antigen [HBsAg] for $>6 \mathrm{mo}$ ) affects about 260000 Canadians, particularly those who were born in $\mathrm{HBV}$-endemic regions and those living in larger urban centres. ${ }^{2}$ Chronic HBV infection can lead to severe liver disease including cirrhosis, liver failure and liver cancer. ${ }^{3}$ Current potent oral antiviral therapies (e.g., nucleos/tide analogues) rarely lead to HBsAg clearance but are highly effective in suppressing $\mathrm{HBV}$ replication and preventing liver disease development. ${ }^{4,5}$ Ongoing monitoring of all chronic HBV carriers is recommended to determine liver disease risk and need for antiviral therapy. Monitoring includes laboratory assessments (alanine aminotransferase
[ALT] levels, HBV DNA levels or viral load, and serology of $\mathrm{HBV}$ e antigen [HBeAg] and $\mathrm{HBV}$ e antibody [HBeAb] $)^{4}$ as well as ultrasonography for liver cancer surveillance based on age and presence of other risk factors (e.g., family history of liver cancer, coinfection). ${ }^{4-7}$

$\mathrm{HBV}$ infection is reportable to the Public Health Agency of Canada, but the prevalence and incidence of the infection in Canada is likely underestimated owing to a lack of standardized

Competing interests: See the end of the article.

This article has been peer reviewed.

Correspondence to: Kelly Burak, kwburak@ucalgary.ca and Carla Coffin, cscoffin@ucalgary.ca

CMAJ Open 2017. DOI:10.9778/cmajo.20170002 
nationwide reporting practices. ${ }^{8}$ The Public Health Agency of Canada estimated rates of chronic HBV infection in $2012^{8}$ but excluded data from Ontario, which has a relatively high prevalence of chronic HBV infection. The 2016 report on HBV by the agency lacked data from 2 provinces (Newfoundland and Labrador, and Prince Edward Island) and 2 territories (Northwest Territories and Nunavut). ${ }^{9}$ Furthermore, as a result of differences in reporting practices, the agency's estimates of the prevalence and incidence of chronic HBV infection in British Columbia were lower than those reported by the BC Centre for Disease Control. ${ }^{10}$

The World Health Organization has advocated for targeted prevention and treatment strategies in an ambitious initiative to eliminate viral hepatitis as a public health threat by $2030 .{ }^{11}$ A key service coverage target is to increase diagnosis of $\mathrm{HBV}$ infection and identify those needing treatment to $30 \%$ by 2020 and $90 \%$ by 2030 .

We hypothesized that there is suboptimal follow-up and referral of chronic HBV carriers in Calgary, a large urban Canadian centre. To increase understanding and appreciation of the burden of chronic HBV disease in Canada, we aimed to identify the number of HBsAg-positive adults in Calgary and to characterize the relevant laboratory investigations performed.

\section{Methods}

\section{Setting and study population}

We conducted a retrospective cohort study that used administrative data to identify all adults (age $>18 \mathrm{yr}$ ) with positive results of testing for HBsAg within the Calgary Zone of Alberta Health Services between Jan. 1 and Dec. 31, 2014. Each individual record included in the Alberta Health Services data repository has a unique identifier (provincial health number) that is given to Alberta residents registered with the Alberta Health Care Insurance Plan, a universal plan that covers more than $99 \%$ of residents. ${ }^{12}$

\section{Data sources}

Available demographic (sex and age) and laboratory (ALT and HBV DNA levels, and HBeAg and HBeAb serology) information for the cohort was extracted from the Alberta Health Services data repository within 6 months of an HBsAgpositive test result. We obtained clinical referral data, including appointment dates, from the Cerner Millennium system, used for clinical scheduling for hepatologists in Calgary. We extracted treatment information from the Alberta Pharmacy Information Network. Provincial registry and laboratory administrative data were cross-referenced with clinical referral data, including data for people who subsequently received antiviral treatment, obtained from the electronic referral and treatment database at the Calgary Liver Unit, Division of Gastroenterology and Hepatology, University of Calgary. The Calgary Liver Unit, serving a catchment area of 1.2 million in southern Alberta, operates a centralized outpatient referral clinic for all patients with viral hepatitis. Details on the Calgary Liver Unit clinic referral structure, patient assessment and treatment database have been previously pub- lished. ${ }^{13-16}$ It is standard clinical practice for all newly referred patients with hepatitis B to undergo liver fibrosis assessment by transient elastography (FibroScan [Echosens]). Serologic testing for $\mathrm{HBsAg}$ and $\mathrm{HBeAb}$ was performed by immunoassay at the Alberta Provincial Laboratory (Abbott Architect), and serum HBV DNA levels were determined by means of the Abbott RealTime HBV assay, with a lower limit of detection of $10 \mathrm{IU} / \mathrm{mL}$ (Abbott Diagnostics).

\section{Statistical analysis}

Clinically significant laboratory test results were defined as an ALT level twice the upper limit of normal $(\geq 38 \mathrm{U} / \mathrm{L}$ in females and $\geq 60 \mathrm{U} / \mathrm{L}$ in males) and an HBV DNA level of $3.3 \log \mathrm{IU} / \mathrm{mL}(2000 \mathrm{IU} / \mathrm{mL})$ or greater. ${ }^{4,5}$ We used the Fisher exact test or $\chi^{2}$ test for categorical data and the Kruskal-Wallis or Student $t$ test for continuous data based on data fulfilment of normal distribution assumptions. Continuous variables were summarized as median and interquartile range (IQR), and categorical variables were expressed as number and percentile. We performed all statistical analyses using Stata 14.1 (StataCorp) with an a priori significance level of 0.05 .

\section{Ethics approval}

The study received ethics approval from the University of Calgary Conjoint Health Research Ethics Board, according to the Declaration of Helsinki.

\section{Results}

A total of 1214 people (584 women [48.1\%]; median age 44 [IQR 36-55] yr) tested positive for HBsAg within the Calgary Zone between Jan. 1 and Dec. 31, 2014. In addition, 24 people $(2.0 \%)$ tested positive for hepatitis $\mathrm{C}$ virus antibody (anti-HCV), indicating previous or current $\mathrm{HCV}$ infection. Of the 24, 19 received HCV RNA testing; all results were positive, thus confirming $\mathrm{HBV}-\mathrm{HCV}$ coinfection.

Of the $1214 \mathrm{HBsAg}$-positive people, 1192 (98.2\%) were tested for ALT, 682 (56.2\%) for HBV DNA, 630 (51.9\%) for $\mathrm{HBeAg}$, and 145 (11.9\%) for HBeAb; 125 people $(10.3 \%)$ received testing for all 4 measures. Test results are given in Figure 1 .

Although 117 people were found to have clinically significant ALT levels, potentially needing consideration for antiviral therapy, 49 (41.9\%) did not have concomitant HBV DNA testing within the assessment period. Despite the incomplete laboratory testing in many cases, 31 people (21 men [67.7\%]; median age 42 [IQR 33-55] yr) were found to have both elevated ALT and elevated HBV DNA levels, thereby potentially meeting criteria for ongoing close follow-up and/or needing referral for consideration of anti-HBV therapy. However, only $13(41.9 \%)$ of the 31 were subsequently treated for $\mathrm{HBV}$ infection.

\section{Treatment and clinical referral}

A total of 144 people (11.9\%) received anti-HBV therapy. The most common antiviral therapy was tenofovir (104 patients [72.2\%]), followed by entecavir (26 [18.0\%]), pegylated- 
interferon (9 $[6.2 \%])$, lamivudine (3 [2.1\%]), adefovir (1 $[0.7 \%])$ and telbivudine (1 [0.7\%]). At last follow-up, the median transient elastography measurement in 121 patients was 6.9 (IQR 4.3-10.2) $\mathrm{kPa}$.

Overall, 390 (32.1\%) of the 1214 people received specialist consultation with a hepatologist between 2011 and 2016, of whom 389 (99.7\%) were tested for ALT, 286 (73.3\%) for HBV DNA, 273 (70.0\%) for HBeAg and 60 (15.4\%) for HBeAb (Table 1). A total of 54/389 patients (13.9\%) had clinically significant ALT elevation, and 231/273 (84.6\%) were $\mathrm{HBeAg}$-negative. Of the 390 patients, 14 (3.6\%) were identified as potentially eligible for antiviral therapy owing to clinically significant ALT and HBV DNA levels; 7 (50\%) of the 14 received anti-HBV treatment.

Of the 824 people who did not see a specialist, 803 (97.4\%) had ALT testing, similar to the proportion of people who saw a specialist. Compared to those with specialist consultation, significantly fewer people without specialist consultation had testing for HBV DNA (396 [48.0\%], $p<0.01$ ), HBeAg (357 [43.3\%], $p<0.01$ ) and HBeAb (85 [10.3\%], $p=0.01$ ) (Table 1). Six (35\%) of the 17 people potentially eligible for antiHBV therapy received antiviral treatment; this proportion was not significantly different from that among people who saw a specialist.

\section{Interpretation}

Of $1214 \mathrm{HBsAg}$-positive people in a single large urban Canadian centre in 2014, only 1 in 10 had testing for all 4 laboratory measures, and most $(67.9 \%)$ had no consultation with a specialist over a 5-year period (2011-2016). Only 13.0\% of those tested for HBeAg had a positive result, but this finding is not surprising given the age of the cohort (median $44 \mathrm{yr}$ ), who would have transitioned to the so-called inactive carrier phase or the later-state $\mathrm{HBeAg}$-negative/reactivation phase. Data are not available on the prevalence of basal core promoter/precore mutations to confirm the latter.

About 300000 people, including those born in Canada and those born elsewhere, moved to Calgary between 2005 and $2015 .{ }^{17}$ Migration - namely, immigration of people from $\mathrm{HBV}$-endemic areas - contributes to an increased incidence of HBV infection in Canada and other Western countries (e.g., United States) as the prevalence of HBV infection among immigrants is generally higher than that of their adoptive country. ${ }^{18,19}$ Interestingly, many developed countries similarly report suboptimal diagnostic and management rates for chronic HBV infection. ${ }^{20-24}$ It is also noteworthy that $19(1.6 \%)$ of our 1214 subjects were found to be coinfected with HCV (i.e., positive for anti-HCV and HCV RNA), another major risk factor

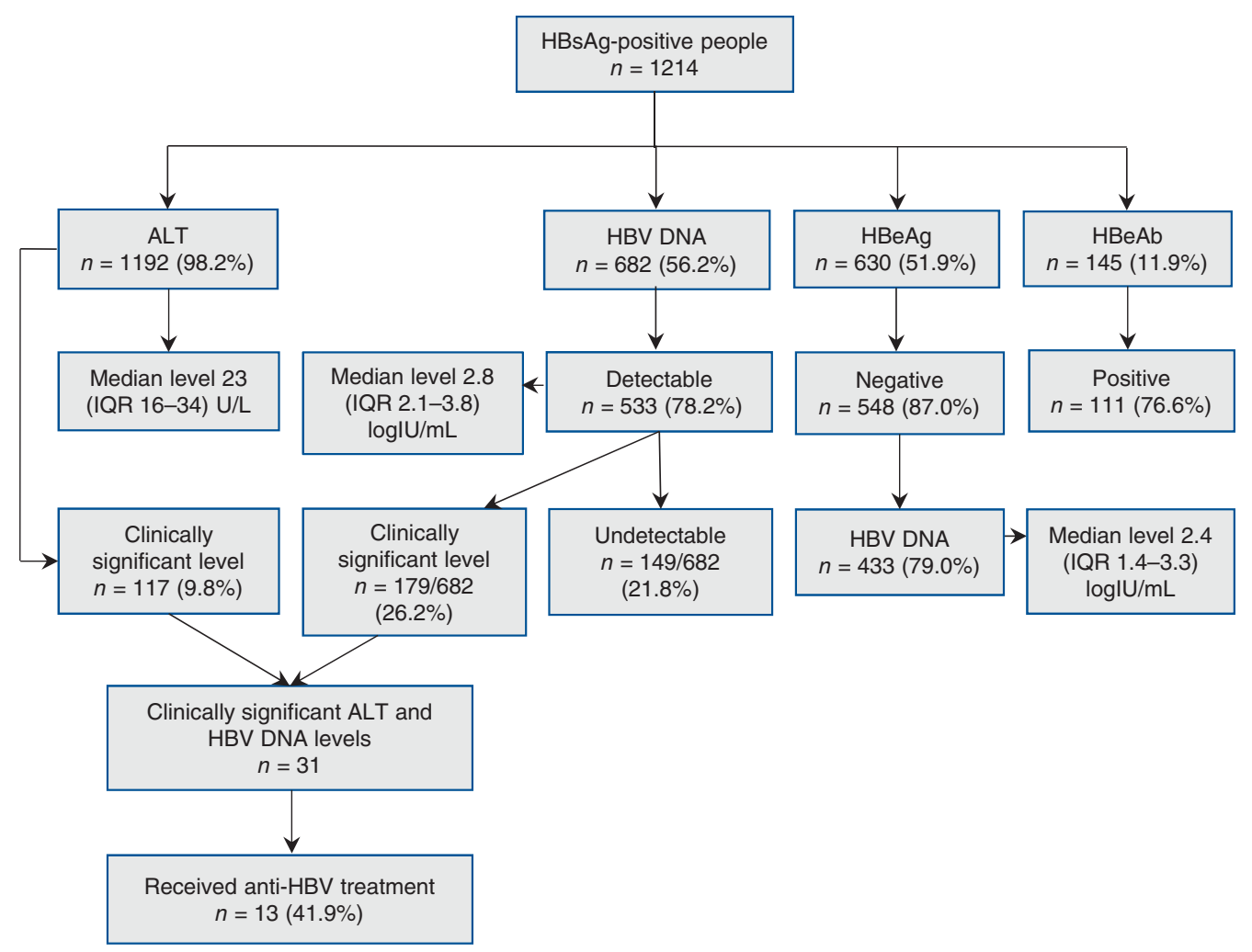

Figure 1: Results of laboratory investigations in 1214 people with positive results of testing for hepatitis $\mathrm{B}$ surface antigen (HBsAg) in Calgary in 2014. $\mathrm{ALT}=$ alanine aminotransferase, $\mathrm{HBeAb}=\mathrm{HBV}$ e antibody, $\mathrm{HBeAg}=\mathrm{HBV}$ e antigen, $\mathrm{HBs} \mathrm{Ag}=$ hepatitis $\mathrm{B}$ surface antigen, $\mathrm{HBV}=$ hepatitis $B$ virus, IQR = interquartile range. 


\section{OPEN}

Research

for chronic liver disease. A study in a US National Veterans cohort showed that chronic HCV carriers with documented $\mathrm{HBV}$ viremia were at significantly higher risk for cirrhosis compared to those with HBV monoinfection. ${ }^{25}$

Our findings are similar to those of a study on care delivery and outcomes among US veterans with chronic HBV infection, in which a low rates of recommended laboratory testing (ALT 97\%, HBV DNA 44\%, HBeAg/anti-HBe $<50 \%$ ) and liver imaging were found. ${ }^{26}$ In both our cohort and the US veterans, a higher proportion of people who received specialist care than of those who did not receive specialist care had HBV DNA and $\mathrm{HBeAg}$ testing. Our findings are also compatible with data from the Hepatitis B Research Network, a prospective observational cohort of 1625 adult chronic HBV carriers in 21 clinical centres in the US and Toronto in which $74 \%$ (50\% male; median age $42 \mathrm{yr}$ ) were HBeAg-negative. ${ }^{27}$

\section{Limitations}

The current study is limited owing to the use of retrospective administrative laboratory data, some of which were not available before 2011. Thus, many of the people identified in the 1-year study period may not have had newly diagnosed chronic HBV infection, and it is unknown whether some had specialist assessment and were deemed not to need antiviral therapy or ongoing close follow-up. Nonetheless, we expect that a substantial number of cases were newly diagnosed because repeat HBsAg testing is not usually necessary, as spontaneous HBsAg loss is rare, reported to occur in less than $1 \%$ of chronic HBV carriers. ${ }^{28-30} \mathrm{~A}$ further limitation is the inability to distinguish between acute and chronic HBV infection. However, the number of acute HBV infections in Canada is expected to be minimal. For example, in 2013, only 27 people were identified as experiencing acute $\mathrm{HBV}$ infection in Alberta. ${ }^{9}$ In fact, it is likely that the current

Table 1: Laboratory assessments performed in 1214 people with positive results of testing for hepatitis B surface antigen in Calgary in 2014, by whether they received a specialist consultation

\begin{tabular}{|c|c|c|c|}
\hline \multirow[b]{2}{*}{ Test; variable } & \multicolumn{2}{|c|}{ No. (\%) of people* } & \multirow[b]{2}{*}{$p$ value } \\
\hline & $\begin{array}{l}\text { Specialist } \\
\text { consultation } \\
n=390\end{array}$ & $\begin{array}{c}\text { No specialist } \\
\text { consultation } \\
n=824\end{array}$ & \\
\hline ALT & $389(99.7)$ & $803(97.4)$ & 0.01 \\
\hline Median level (IQR), U/L & $23.5(17-36)$ & $22(16-33)$ & 0.02 \\
\hline $\begin{array}{l}\text { Level } \geq 2 \text { times upper limit of } \\
\text { normal† }\end{array}$ & $54(13.9)$ & $63(7.8)$ & $<0.01$ \\
\hline HBV DNA & $286(73.3)$ & $396(48.0)$ & $<0.01$ \\
\hline Median level (IQR), logIU/mL & $2.4(1.1-3.5)$ & $2.5(1.5-3.4)$ & 0.4 \\
\hline$<1$ loglUmL & $79(27.6)$ & 75 (18.9) & $<0.01$ \\
\hline$\geq 3.3 \log \mathrm{IUmL} \dagger$ & 77 (26.9) & $103(26.0)$ & 0.8 \\
\hline HBeAg & $273(70.0)$ & $357(43.3)$ & $<0.01$ \\
\hline Negative result & $231(84.6)$ & $317(88.8)$ & 0.2 \\
\hline HBeAb & $60(15.4)$ & $85(10.3)$ & 0.01 \\
\hline Positive result & $45(75.0)$ & $66(77.6)$ & 0.8 \\
\hline $\begin{array}{l}\text { HBV DNA testing in people with } \\
\text { ALT level } \geq 2 \text { times upper limit } \\
\text { of normal }\end{array}$ & $37(68.5)$ & $31(49.2)$ & 0.04 \\
\hline Median level (IQR), loglU/mL & $2.8(1.5-4.9)$ & $4.1(1.4-5.8)$ & 0.5 \\
\hline$<1$ loglUmL & 7 (18.9) & $6(19.4)$ & 1.0 \\
\hline 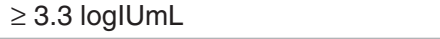 & $14(37.8)$ & $17(54.8)$ & 0.2 \\
\hline $\begin{array}{l}\text { HBV DNA testing in HBeAb- } \\
\text { negative people }\end{array}$ & $186(80.5)$ & $247(77.9)$ & 0.5 \\
\hline Median level (IQR), loglU/mL & $2.5(1.2-3.3)$ & $2.5(1.6-3.3)$ & 0.3 \\
\hline$<1$ loglUmL & $51(27.4)$ & $39(15.8)$ & $<0.01$ \\
\hline$\geq 3.3 \log I U m L$ & $46(24.7)$ & $60(24.3)$ & 0.9 \\
\hline $\begin{array}{l}\text { Note: ALT = alanine aminotransferase, HBV } \\
\text { interquartile range. } \\
\text { "Except where noted otherwise. } \\
\text { †Clinically significant level. }\end{array}$ & itis $B$ virus, $\mathrm{HBeA}$ & body, $\mathrm{HBeAg}=$ & , IQR = \\
\hline
\end{tabular}


study may underestimate the burden of HBsAg-positive cases. We excluded all those with a positive result of testing for HBsAg who did not have an ordering physician based in the Calgary Zone or were not registered within the Calgary Zone or the provincial health care system (i.e., did not have a provincial health number). Furthermore, just before the study, some people may have moved within the province or had specialist assessment or testing in a laboratory or health care facility outside the designated health care region, thereby influencing our results. Nevertheless, the findings suggest that there are significant gaps in care for chronic HBV carriers.

We do not have current data on the number of people who had ultrasound surveillance for liver cancer. This is an area of investigation by coauthors of the current study (A.A.A. and K.W.B.) using an automated liver cancer screening database in partnership with a specialist radiology/ultrasound referral clinic in Calgary. Future directions of study will include exploring the cost-effectiveness of HBV screening and/or surveillance in Alberta and Canada. Future studies will have a longer follow-up period, capturing all available laboratory and provincial health administrative data from 2011. The results will be used to provide feedback to public health and primary care physicians regarding appropriate screening, testing and referral for chronic HBV carriers.

\section{Conclusion}

Our study suggests that the burden of chronic HBV infection is substantial in a single urban centre in Canada. The findings indicate that management of HBV infection in Canada, a developed nation, falls short of the standards of the World Health Organization. To achieve the World Health Organization goal of elimination of viral hepatitis by 2030, further, stringent preventive actions and disease surveillance are required, not only in $\mathrm{HBV}$-endemic areas but also in Canada and other developed nations. The current study contributes to filling the knowledge gap regarding the epidemiologic characteristics of HBV infection in Canada and highlights the need for a concerted public health effort for surveillance and treatment of chronic HBV infection.

\section{References}

1. Hepatitis B: fact sheet. Geneva: World Health Organization [updated 2016]. Available: www.who.int/mediacentre/factsheets/fs204/en/\# (accessed 2016 Dec. 12).

2. Schweitzer A, Horn J, Mikolajczyk RT, et al. Estimations of worldwide prevalence of chronic hepatitis B virus infection: a systematic review of data published between 1965 and 2013. Lancet 2015;386:1546-55.

3. Jemal A, Bray F, Center MM, et al. Global cancer statistics. CA Cancer 7 Clin 2011;61:69-90

4. Coffin CS, Fung SK, Ma MM. Management of chronic hepatitis B: Canadian Association for the Study of the Liver consensus guidelines. Can 7 Gastroenterol 2012;26:917-38.

5. Terrault NA, Bzowej NH, Chang KM, et al. AASLD guidelines for treatment of chronic hepatitis B. Hepatology 2016;63:261-83.

6. Sherman M. Hepatocellular carcinoma: epidemiology, surveillance, and diagnosis. Semin Liver Dis 2010;30:3-16.

7. Bruix J, Sherman M. Management of hepatocellular carcinoma: an update. Hepatology 2011;53:1020-2.

8. Report on Hepatitis $B$ and $C$ in Canada: 2012. Ottawa: Public Health Agency of Canada; 2016. Available: http://publications.gc.ca/collections/collection_2016/ aspc-phac/HP37-22-2012-eng.pdf (accessed 2017 Feb. 25).

9. Report on Hepatitis B and C in Canada: 2013. Ottawa: Public Health Agency of
Canada; 2016. Available: http://publications.gc.ca/collections/collection_2016/ aspc-phac/HP37-22-2013-eng.pdf (accessed 2017 Feb. 25).

10. British Columbia annual summary of reportable diseases 2014. Vancouver: Communicable Disease Prevention and Control Services; 2015. Available: www.bccdc. $\mathrm{ca} /$ resource-gallery/Documents/Statistics\%20and\%20Research/Statistics\% 20and\%20Reports/Epid/Annual\%20Reports/AR2014FinalSmall.pdf (accessed 2017 Feb. 25).

11. Combating hepatitis B and C to reach elimination by 2030. Geneva: World Health Organization; 2016. Available: www.who.int/hepatitis/publications/ hep-elimination-by-2030-brief/en/\# (accessed 2016 Jun. 28).

12. Research Access and Policy Support Unit. Alberta Health and Wellness data disclosure handbook. Edmonton: Alberta Health and Wellness; 2003:1-15.

13. Coffin CS, Rezaeeaval M, Pang JX, et al. The incidence of hepatocellular carcinoma is reduced in patients with chronic hepatitis B on long-term nucleos(t)ide analogue therapy. Aliment Pharmacol Ther 2014;40:1262-9.

14. Congly SE, Wong P, Al-Busafi SA, et al. Characterization of hepatitis B virus genotypes and quantitative hepatitis B surface antigen titres in North American tertiary referral liver centres. Liver Int 2013;33:1363-9.

15. Samadi Kochaksaraei G, Castillo E, Osman M, et al. Clinical course of 161 untreated and tenofovir-treated chronic hepatitis B pregnant patients in a low hepatitis B virus endemic region. 7 Viral Hepat 2016;23:15-22.

16. Pang JXQ, Zimmer S, Niu S, et al. Liver stiffness by transient elastography predicts liver-related complications and mortality in patients with chronic liver disease. PLoS One 2014;9:e95776.

17. 2015 civic census results. Calgary: City of Calgary; 2015. Available: www.calgary. $\mathrm{ca} / \mathrm{CA} /$ city-clerks/Pages/Election-and-information-services/Civic-Census/ 2015-Results.aspx (accessed 2017 Feb. 25).

18. Sharma S, Carballo M, Feld JJ, et al. Immigration and viral hepatitis. 7 Hepatol 2015;63:515-22

19. Ip S, Ford JA, Lau K, et al. Seroprevalences of hepatitis B virus and hepatitis C virus among participants of an Asian health fair in the Lower Mainland, British Columbia. Can 7 Infect Dis Med Microbiol 2015;26:196-200.

20. Papatheodoridis GV, Tsochatzis E, Hardtke S, et al. Barriers to care and treatment for patients with chronic viral hepatitis in Europe: a systematic review. Liver Int 2014;34:1452-63.

21. $\mathrm{Vu} \mathrm{VD}, \mathrm{Do} \mathrm{A}, \mathrm{Nguyen} \mathrm{NH}$, et al. Long-term follow-up and suboptimal treatment rates of treatment-eligible chronic hepatitis B patients in diverse practice settings: a gap in linkage to care. BM7 open Gastroenterol 2015;2:e000060.

22. Wu Y, Johnson KB, Roccaro G, et al. Poor adherence to AASLD guidelines for chronic hepatitis B management and treatment in a large academic medical center. Am 7 Gastroenterol 2014;109:867-75.

23. Hyun CS, Kim S, Kang SY, et al. Chronic hepatitis B in Korean Americans: decreased prevalence and poor linkage to care. BMC Infect Dis 2016;16:415.

24. Cohen C, Holmberg SD, McMahon BJ, et al. Is chronic hepatitis B being undertreated in the United States? F Viral Hepat 2011;18:377-83.

25. Kruse RL, Kramer JR, Tyson GL, et al. Clinical outcomes of hepatitis B virus coinfection in a United States cohort of hepatitis C virus-infected patients. Hepatology 2014;60:1871-8.

26. Serper M, Choi G, Forde KA, et al. Care delivery and outcomes among US veterans with hepatitis B: a national cohort study. Hepatology 2016;63:1774-82.

27. Ghany MG, Perrillo R, Li R, et al. Characteristics of adults in the Hepatitis B Research Network in North America reflect their country of origin and hepatitis B virus genotype. Clin Gastroenterol Hepatol 2015;13:183-92.

28. Liaw YF, Sheen IS, Chen TJ, et al. Incidence, determinants and significance of delayed clearance of serum HBsAg in chronic hepatitis B virus infection: a prospective study. Hepatology 1991;13:627-31.

29. Yu MW, Hsu FC, Sheen IS, et al. Prospective study of hepatocellular carcinoma and liver cirrhosis in asymptomatic chronic hepatitis B virus carriers. $\mathrm{Am}$ 7 Epidemiol 1997;145:1039-47.

30. Villeneuve JP, Desrochers M, Infante-Rivard C, et al. A long-term follow-up study of asymptomatic hepatitis B surface antigen-positive carriers in Montreal. Gastroenterology 1994;106:1000-5.

Affiliations: Calgary Liver Unit (Lau, Shaheen, Aspinall, Congly, Borman, Jayakumar, Eksteen, Lee, Stinton, Swain, Burak, Coffin), Division of Gastroenterology and Hepatology, Department of Medicine; Department of Microbiology, Immunology and Infectious Diseases (Lau, Coffin), Cumming School of Medicine, University of Calgary; Alberta Health Services (Ricento, Qureshi), Calgary, Alta.

Contributors: Abdel Aziz Shaheen, Kelly Burak and Carla Coffin were responsible for the study conception and design. Keith Lau and Abdel Aziz Shaheen were responsible for statistical analysis. Keith Lau, Abdel Aziz Shaheen and Carla Coffin analyzed and interpreted the data, and drafted and revised the manuscript. All of the authors acquired the data, approved the final version to be published and agreed to act as guarantors of the work.

Competing interests: Carla Coffin has served as a speaker and advisory board member and/or has received research support from Bristol-Myers 
Squibb, GlaxoSmithKline, Gilead Sciences, Janssen and Merck. Mark Swain has served as a speaker and advisory board member and/or has received research support from Bristol Myers Squibb, Gilead Sciences, CymBay Therapeutics, Intercept Pharmaceuticals, Abbvie and Merck. He is a data and safety monitoring committee member in clinical trials for Gilead Sciences and GRI Bio. Stephen Congly reports grants from Gilead Sciences and Hyperion Therapeutics, and personal fees from Allergan and Astellas Pharma Canada outside the submitted work. Meredith Borman reports personal fees from Merck Canada and nonfinancial support from Astellas Pharma Canada outside the submitted work. Samuel Lee reports grants and personal fees from Bristol-Myers Squibb, Gilead Sciences and Roche outside the submitted work. Kelly Burak reports grants from Verlyx Pharma, Lupin Pharma Canada and Bayer, and personal fees from Astellas
Pharma Canada, Gilead Sciences, Bayer, Amgen and Merck outside the submitted work. No other competing interests were declared.

Funding: Keith Lau is supported by the Canadian Institutes of Health Research (CIHR) Canada Graduate Scholarship - Master's Award. Carla Coffin is supported by the CIHR New Investigator Award and CIHR Operating grant 354777 (Biomedical/Clinical).

Acknowledgement: The authors thank all clinic and research staff members of the Calgary Liver Unit.

Supplemental information: For reviewer comments and the original submission of this manuscript, please see www.cmajopen.ca/content $/ 5 / 2 /$ E431/suppl/DC1 